\title{
DCPTA Suppresses Growth and Flowering of Amaryllis
}

\author{
Alan W. Meerow and Sven E. Svenson \\ University of Florida, Institute of Food and Agricultural Sciences, Fort \\ Lauderdale Research and Education Center, 3205 College Avenue, Fort \\ Lauderdale, FL 33314

\section{Michael E. Kane \\ Department of Environmental Horticulture, 1545 Fifield Building, Gainesville, FL 32611}

Additional index words. tertiary amine bioregulator, Hippeastrum, flower bulb, production, flowering physiology

\begin{abstract}
DCPTA is a synthetically produced tertiary amine bioregulator with potential for increasing crop productivity at high light intensities. DCPTA reduces the number of days from planting to maturity in various potted ornamental crops, including 'Fortune' daffodil (Narcissus L.), 'Sonora' tulip (Tulipa L.), and 'Jan Bos' hyacinth (Hyacinthus orientalis L.). Our objective was to examine how light intensity and DCPTA application influence growth and flowering of amaryllis (Hippeastrum hybridum Hort.). Flowering size bulbs of a micropropagated amaryllis clone were treated with $30 \mu_{\mathrm{M}}$ or no DCPTA and grown in full sun or $63 \%$ shade for 1 year. Number of scapes produced, flowers per scape, change in bulb fresh weight, number of bulblets produced, and bulblet weight were recorded and analyzed. There were no significant differences in days to first flowering or in number of flowers produced per scape among the treatments. DCPTA application at the recommended rate significantly reduced number of emergent inflorescences and the bulb biomass increase of hybrid amaryllis. Additionally, the interaction between light level and DCPTA appeared weak for amaryllis, and was only slightly significant relative to bulblet production. Chemical name used: 2-(3,4-dichlorophenoxy)triethylamine (DCPTA).
\end{abstract}

Hippeastrum Herbert, the amaryllis, is one of the most important minor bulb crops for indoor forcing and landscape color in the U.S. Dept. of Agriculture's zones 8 to 11 (Meerow, 1988; Traub, 1958). Several plant growth regulators (PGRs) have desirable effects on amaryllis, although none are currently used in commercial production (Okubo, 1993). Bose et al.(1980) reported that soaking Hippeastrum 'Fire Dance' bulbs in $1 \mathrm{H}$-indole-3-acetic acid (IAA) increased weight and number of bulblets, soaking in gibberellic acid $\left(\mathrm{GA}_{3}\right)$ increased bulb weight and flower diameter, and soaking in 2-chloro- $N, N, N$-trimethylethanaminium chloride [chormequat chloride (CCC)] increased flower count. IAA and $\mathrm{GA}_{3}$ foliar sprays increased offset bulblet production, and CCC or (2-chloroethyl) phosphonic acid (ethephon) sprays increased bulblet weight. IAA, $\mathrm{GA}_{3}$, and $\mathrm{CCC}$ sprays also increased flower counts and size (Bose et al., 1980).

DCPTA is a synthetically produced tertiary amine bioregulator with potential for increasing crop productivity at high light in-

Received for publication 4 Nov. 1993. Accepted for publication 29 Apr. 1994. Florida Agriculture Expt. Station Journal Series no. R-03464. The cost of publishing this paper was defrayed in part by the payment of page charges. Under postal regulations, this paper therefore must be hereby marked advertisement solely to indicate this fact. tensities (Keithly and Yokoyama, 1990). The mode of DCPTA action is unknown, but it has been suggested that enhancement of crop performance by tertiary amines may involve secondary promoter compounds that control longterm growth (Keithly et al., 1991c). DCPTA reduces the number of days from planting to maturity in various potted ornamental crops (Keithly et al., 1991c), including temperate bulbous crops such as daffodil, tulip, and hyacinth, but, to our knowledge, no tropical bulbs have been studied. High irradiance may be required for full expression of plant responses to DCPTA (Gausman et al., 1991), but this aspect of tertiary amine regulation on plant growth has received little study. Our objective was to examine how light intensity and DCPTA application influenced amaryllis growth and flowering.
In Aug. 1992, flowering-size bulbs of micropropagated $\mathrm{F}_{1}$ hybrid Hippeastrum H-8-14 [H. cardenasianum (Amaryllis cardenasiana Traub) $\times$ H. papilio (Amaryllis papilio Ravenna)] were lifted from the field where they had been grown under $30 \%$ shade for 2.5 years. All leaves, roots, and bulblets were removed, and the bulbs were cleaned and cured at ambient temperatures in $85 \%$ shade for 4 weeks. Only bulbs with a diameter $>3.0$ $\mathrm{cm}$ at the widest point were used for the experiment. In September, the bulbs were weighed, and soaked for $2 \mathrm{~h}$ in a $30-\mu \mathrm{M}$ aqueous solution of DCPTA plus $0.1 \%$ Tween 80 or a solution of $0.1 \%$ Tween 80 alone. The DCPTA rate used was based on the recommendations in Keithly and Yokoyama (1990) and Keithly et al. (1990a, 1990b; 1991a, 1991b). The bulbs were air-dried overnight and then were potted. Bulbs were planted in 7.5-liter containers using a 5 pine bark : 4 sedge peat : 1 sand (by volume) medium amended with $880 \mathrm{~g}$ Micromax (Grace Sierra, Milpitas, Calif.) and $4.9 \mathrm{~kg}$ dolomite $/ \mathrm{m}^{3}$. Fifteen replicate containers of each DCPTA treatment were grown under full sun [maximum photsynthetic photon flux $(\mathrm{PPF})=2100$ $\mu \mathrm{mol} \cdot \mathrm{m}^{-2} \cdot \mathrm{s}^{-1}$ ] or $63 \%$ shadecloth. Replications were arranged in a completely randomized design within each light environment. All pots were top-dressed with $36 \mathrm{~g}$ Osmocote (Grace Sierra) $17 \mathrm{~N}-2.3 \mathrm{P}-10 \mathrm{~K} 1$ month after planting and again after 6 months. The plants were exposed to rainfall or received overhead irrigation as needed. Date of flowering and flower count was recorded for each scape produced during the experiment. The experiment ended in Sept. 1993. Bulbs were lifted and cleaned of roots and leaves, and all bulblets were counted and then removed. Bulbs and all bulblets produced were weighed for each replication. Data were analyzed by analysis of variance and Waller-Duncan k ratio means separation.

\section{Results and Discussion}

Days to first flowering and number of flowers produced per scape (data not shown) were similar for all treatments. The earliest and latest scapes appeared in late March and August, respectively. However, the number of scapes varied significantly between the two DCPTA treatments, regardless of light level

Table 1. Effects of light intensity and DCPTA on growth and flowering of Hippeastrum H-8-14.

\begin{tabular}{|c|c|c|c|c|c|}
\hline Treatment & No. scapes & $\begin{array}{l}\text { Increase in } \\
\text { main bulb } \\
\text { fresh wt (g) }\end{array}$ & $\begin{array}{c}\text { No. } \\
\text { bulblets }\end{array}$ & $\begin{array}{c}\text { Bulblet } \\
\text { wt (g) }\end{array}$ & $\begin{array}{c}\text { Increase } \\
\text { in total } \\
\text { wt }(\mathrm{g})\end{array}$ \\
\hline \multicolumn{6}{|l|}{$63 \%$ Shade } \\
\hline Control & $2.3 \mathrm{a}^{\mathrm{z}}$ & $317 \mathrm{a}$ & $5.5 \mathrm{c}$ & $198 \mathrm{~b}$ & $515 \mathrm{ab}$ \\
\hline DCPTA & $1.4 \mathrm{~b}$ & $218 \mathrm{c}$ & $5.7 \mathrm{bc}$ & $192 \mathrm{~b}$ & $423 \mathrm{~b}$ \\
\hline \multicolumn{6}{|l|}{ Full sun } \\
\hline Control & $2.5 \mathrm{a}$ & $283 \mathrm{ab}$ & $9.6 \mathrm{a}$ & $292 \mathrm{a}$ & $575 \mathrm{a}$ \\
\hline DCPTA & $1.5 \mathrm{~b}$ & $230 \mathrm{bc}$ & $7.5 \mathrm{~b}$ & $206 \mathrm{~b}$ & $429 b$ \\
\hline \multicolumn{6}{|l|}{ Overall effects } \\
\hline Light level & NS & NS & 0.0001 & 0.0195 & NS \\
\hline DCPTA & 0.0001 & 0.0011 & 0.1999 & 0.0468 & 0.0033 \\
\hline Light $\times$ DCPTA & NS & NS & 0.1092 & 0.0793 & NS \\
\hline
\end{tabular}

${ }^{\mathrm{z}}$ Mean separations within columns by the Waller-Duncan $\mathrm{k}$ ratio method $(\mathrm{k}=100)$.

HortSCIENCE, Vol. 29(10), October 1994 
(Table 1). DCPTA inhibited scape emergence from treated bulbs. DCPTA also lowered the net increase in bulb weight, but the increase was significant only in $63 \%$ shade. Number of bulblets was significantly affected by light level, but significant difference in mean bulblet count and weight relative to DCPTA treatment occurred only in full sun (Table 1). When fresh weight of the main bulb and the bulblets were combined, it seemed DCPTA negatively affected total fresh weight gain, especially under full sun. Although leaf and root biomass were not included in the data, leaf count was similar among the treatments (data not shown).

To our knowledge, no negative effects of DCPTA on the flowering of any particular crop have been reported. Kobayashi et al. (1981) reported no effect on eggplant's vegetative growth, despite an increase in fruit set, and Richter et al. (1987) reported no effects from foliar application on 2-year-old red pine seedlings.

Keithly et al. (1991c) reported a reduction in days to $50 \%$ anthesis of flowers on three temperate bulb crops that are strongly thermoperiodic and initiate their floral axes during summer dormancy (Rees, 1972, 1985). Consequently, DCPTA treatment shortly before planting the bulbs would not affect the initiation of the first inflorescences emerging after treatment. Effects on second-year flowering after DCPTA treatment (i.e., effects on floral initiation) were not reported for these crops. Tropical bulbs, such as amaryllis, initiate sympodia consisting of four leaves and a lateral inflorescence throughout their active growth period (Okubo, 1993; Rees, 1972), alternating between leaf formation and flower initiation. Initiation of at least one scape probably occurred during the active growth period (October-February) after our DCPTA treatment.

DCPTA application at the recommended rate significantly reduced the number of emergent inflorescences and the bulb biomass increase of hybrid amaryllis. Additionally, the light level $\times$ DCPTA interaction was weak for amaryllis and was only slightly significant for bulblet production.

\section{Literature Cited}

Bose, T.K., B.K. Jana, and T.P. Mukhopadhyay. 1980. Effects of growth regulators on growth and flowering in Hippeastrum hybridum Hort. Scientia Hort. 12:195-200.

Gausman, H.W., J.E. Quisenberry, and H. Yokoyama. 1991. Introduction to effects of plant biochemical regulators, p. 1-16. In: H.W. Gausman (ed.). Plant biochemical regulator. Marcel Dekker, New York.

Keithly, J.H. and H. Yokoyama. 1990. Regulation of plant productivity I: Improved seedling vigor and floral performance of Phalaenopsis by 2 (3,4-dichlorophenoxy)triethylamine [DCPTA]. Plant Growth Regulat. 9:19-26.

Keithly, J.H., H. Yokoyama, and H.W. Gausman. 1990a. Effect of 2-(3,4-dichlorophenoxy) triethylamine [DCPTA] upon the growth and development of sugar beet. Plant Sci. 68:57-64.

Keithly, J.H., H. Yokoyama, and H.W. Gausman. 1990b. Enhanced yield of tomato in response to 2-(3,4-dichlorophenoxy)triethylamine [DCPTA]. Plant Growth Regulat. 9:127-136.

Keithly, J.H., D.P. Jones, and H. Yokoyama. 1991a. Survival and growth of transplanted orchid seedlings enhanced by DCPTA. HortScience 26:1284-1286.

Keithly, J.H., H. Kobayashi, H. Yokoyama, and H.W. Gausman. 1991b. Enhanced vegetative growth and development of processing tomato by DCPTA treatment of seed. J. Amer. Soc. Hort. Sci. 116:693-696.

Keithly, J.H., H. Yokoyama, and H.W. Gausman. 1991c. Regulation of crop growth and yield by tertiary amine bioregulators, p. 223-246. In: H.W. Gausman (ed.). Plant biochemical regulators. Marcel Dekker, New York.

Kobayashi, H., J.H. Keithly, and H. Yokoyama. 1991. Improvements in the fruit set and harvest index of eggplant by 2-(3,4-dichlorophenoxy) triethylamine [DCPTA]. J. Jpn. Soc. Hort. Sci. 60:77-81.

Meerow, A.W. 1988. New trends in amaryllis (Hippeastrum) breeding. Proc. Fla. State Hort. Soc. 101:285-288.

Okubo, H. 1993. Hippeastrum (amaryllis), p. 321334. In: A.A. De Hertogh and M. Le Nard (eds.). The physiology of flower bulbs. Elsevier, Amsterdam, The Netherlands.

Rees, A.R. 1972. The growth of bulbs. Academic, London.

Rees, A.R. 1985. Hippeastrum, p. 294-296. In: A.H. Halevy (ed.). CRC handbook of flowering, vol. 1. CRC Press, Boca Raton, Fla.

Richter, D.D., L.J. Ramseyer, J.R. Johnson, C.E. Olsen, and Z. Zhou. 1987. Growth responses of red pine seedlings to the chemical bioregulator DCPTA. New Forests 4:301-309.

Traub, H.P. 1958. The amaryllis manual. Macmillan, New York. 